$\xi=$ 잘

\title{
Evaluation of patient's perception and experience towards anterior microimplants for intrusion: A questionnaire study
}

\author{
Dave Chinmay S *, Vaghani Bhavnit, Patel Kartik, Santosh Goje, Purvesh Shah, Bhumi Modi \\ K. M. Shah Dental College \& Hospital, Vadodara, India \\ *Corresponding author E-mail: csd765@gmail.com
}

\begin{abstract}
Introduction: Implants have gained popularity in orthodontics because they facilitate maximum anchorage with minimum patient cooperation. However, some orthodontists avoid using implants because perception and experience of patients towards such anchorage systems is questionable and is not been fully reported.

Aim and objectives: To evaluate the patient's perception and experience towards the treatment with anterior microimplants for intrusion of anterior teeth using questionnaire.

Materials and methods: After considering the inclusion and exclusion criteria, Participants who are undergoing orthodontic treatment with anterior implants for the intrusion of the maxillary anterior teeth was selected for the study. Questionnaire which was validated from ten respondents and subject experts will be given to each participant and asked to fill it. After collection of filled questionnaire, all the data was subjected to statistical analysis.

Results: Most of the patients had enough confidence on their orthodontist and did not think to take a second opinion when an anterior implant was recommended. Majority of the patients were concerned to know regarding advantages and disadvantages of anterior microimplant and inquired about the time for the placement of anterior microimplant. More patients were worried about how long the anterior microimplant will remain inserted in their mouth and had fear of local anesthesia. On loading of microimplant, most of the patients felt pressure at the implant and few felt pain.

Conclusion: The procedure was pleasant and comfortable for large number of patients and they did not felt pain after placement of anterior microimplant. Majority of the patients were satisfied with the treatment and would recommend it to other patients. Highest number of patients got used to the anterior implant by day 7 followed by day 15 . An average acceptable time period for the anterior microimplant was 12 months. The overall perception and experience by the patients to the placement of anterior microimplant can be rated as expected and good.
\end{abstract}

Keywords: Anterior microimplant; perception and experience; questionnaire study

\section{Introduction}

Implants have gained popularity in orthodontics because they facilitate maximum anchorage with minimum patient cooperation. However, some orthodontists avoid using implants because perception and experience of patients towards such anchorage systems is questionable and is not been fully reported (TakanoYamamoto T et al 2002 p.26; Gündüz E et al 2004 p.623).

Placement of microimplants in the mid-anterior region between the roots of two central incisors is a common site for true intrusion of upper anterior teeth to correct cases of deep bite. Anatomically, this is a safe area for insertion of microimplants but there might be trauma to the frenum and movement of upper lip may be affected. Placement of microimplant is always done under local anesthesia, with or without an incision. Injection of LA, placement of incision, insertion of screw, all can create apprehension in the patient's mind. Microimplants once inserted can remain in their insertion sites throughout the treatment as it may be needed again during treatment and removed only when the orthodontic treatment is over (Miyawaki S et al 2003 p.373; Liou EJ et al 2004 p.42). During this period the patient can experience irritation to the frenum and upper lip from the implant. Food lodgment and lack of proper oral hygiene can also cause irritation in the implant site. This can affect the patients' reluctance in accepting and coping with these devices (Freundenthaler JW et al 2001 p.358; Kuroda S et al 2007 p.9; Hyo-Sang P et al 2010 p.200).

In addition to this, the attachments like E-chain or NiTi closed coil spring can also cause irritation to the patient. All these might be the reasons for the apprehension experienced by the patient and can affect their perception and experience for the anterior microimplants. The literature has no reports addressing these behavioral and physiological responses of the patients to the treatment using microimplants in the anterior region and its acceptance. Hence an attempt is made here to conduct a study to evaluate the patient's perception and experience towards the treatment with anterior microimplants for intrusion of anterior teeth using questionnaire.

\section{Materials and method}

The study was conducted in K. M. Shah Dental College \& Hospital, Vadodara. Participants involved in the study were selected from the patient undergoing treatment with anterior implant for intrusion in Department of Orthodontics \& Dentofacial Orthopedics. 
Inclusion criteria were:

1) Participants with extruded maxillary anterior teeth who are undergoing orthodontic treatment with anterior microimplants for intrusion.

2) Participants who know the English language.

Exclusion criteria were:

1) Subjects with systemic disease or congenital syndrome.

2) Subjects with physical disability.

3) Subjects with mental retardation.

4) Subjects who refuse to give consent

Participant information sheet was given to each participant Questionnaire which was validated from ten respondents and subject experts and then it was given to each participant and asked to fill it. As it is close ended questionnaire, subjects were instructed to select only one option to the questions. After collection of filled questionnaire, all the data were subjected to statistical analysis. Answers to each question were evaluated individually to conclude the study. The questionnaire which was asked to the patients to fill is given bellow.

Name of the participant:

Age/sex:

Date:

Questionnaire:

- Before placement of anterior microimplant

1) Did you develop a doubt when you were informed about placement of anterior microimplant in your mouth?

- Yes

- No

2) Did you think of taking a second opinion when your orthodontist recommended an anterior implant?

- Yes

- No

3) Did you ask your orthodontist regarding advantages and disadvantages of anterior microimplant?

- Yes

- No

4) Did you inquire about the time for the placement of anterior microimplant?

- Yes

- No

5) Were you worried about how long the anterior microimplant will remain in your mouth?

- Yes

- No

6) Did you develop fear in your mind when you came to know that the procedure will be done under local anaesthesia?

- Yes

- No

- After placement of anterior microimplant

7) Was the procedure pleasant and comfortable for you?

- Yes

- No

8) Did you feel pain during or after placement of anterior microimplant?

- Yes

- ${ }^{-}$
9) What was your feeling when an orthodontic attachment was put from the anterior implant to the teeth for force application?

- Pressure at the implant

- Pain in the teeth

- Both

10) Are you satisfied with the treatment by anterior implant so far?

- Yes

- No

11) Would you recommend it to other patients?

- Yes

- No

12) By what day did you get used to the anterior implant?

- Day 1

- Day 2

- $\quad$ Day 3

- $\quad$ Day 4

- Day 5

- Day 6

- $\quad$ Day 7

- Day 15

- Day 30

- Could not get used to it.

13) What is the time period do you think is acceptable for anterior implant?

- 1 month

- 2 months

- 4 months

- 6 months

- 12 months

- 24 months

- Till the orthodontic treatment is over.

\section{Results}

Table 1: Mean age of the sample

\begin{tabular}{cccccc}
\hline & $\mathrm{N}$ & Minimum & Maximum & Mean & Std. Deviation \\
\hline Age & 86 & 15 & 36 & 21.5 & 3.91 \\
\hline
\end{tabular}

A table 1 shows that the mean age of the overall sample included in the study was 21.5 years. Age ranged from 15 years to 36 years.

Table 2: Gender distribution of the sample

\begin{tabular}{ccc}
\multicolumn{3}{c}{ Table 2: Gender distribution of the sample } \\
\hline Sex & Frequency $(\mathrm{N})$ & Percentage $(\%)$ \\
\hline Female & 50 & 58.13 \\
Male & 36 & 41.87 \\
Total & 86 & 100.0 \\
\hline
\end{tabular}

Table 2 shows that out of total 86 samples, 50 (58.13\%) were females and $36(41.87 \%)$ were males. 


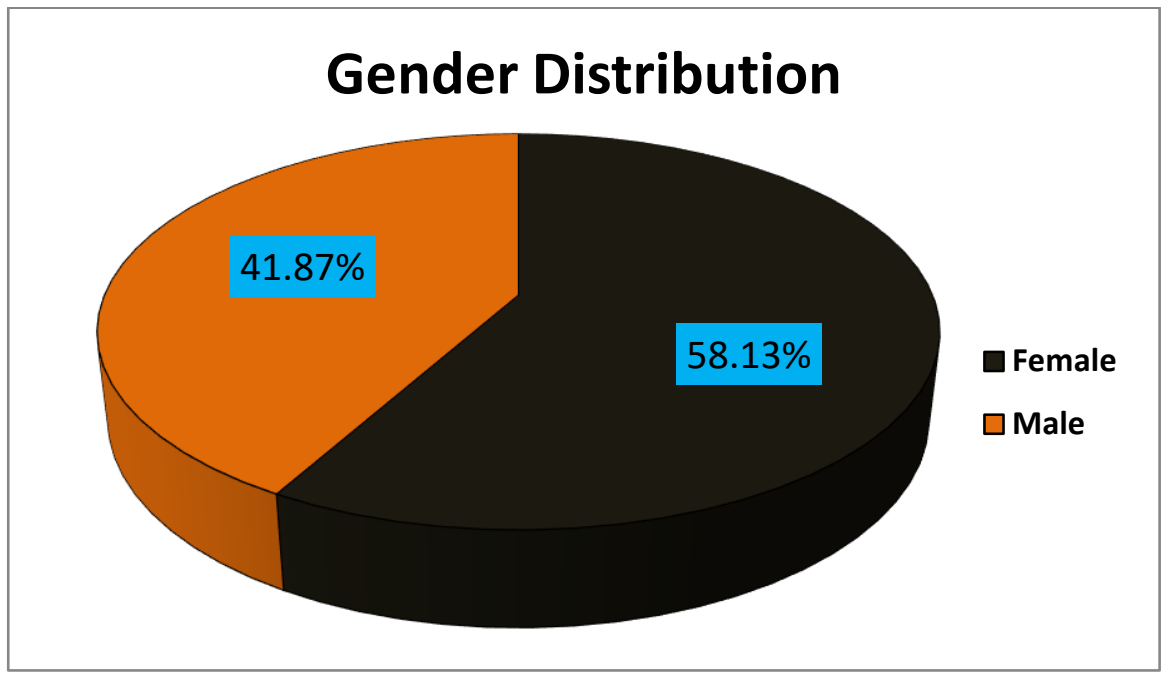

Chart 1: Pie chart showing gender distribution of the sample

Questionnaire:

- Before placement of anterior microimplant

1) Did you develop a doubt when you were informed about placement of anterior microimplant in your mouth?

- $\quad$ Yes $\rightarrow 61$ samples $\rightarrow 70.93 \%$

- No $\rightarrow 25$ samples $\rightarrow 29.07 \%$

2) Did you think of taking a second opinion when your orthodontist recommended an anterior implant?

- $\quad$ Yes $\rightarrow 39$ samples $\rightarrow 45.35 \%$

- $\quad$ No $\rightarrow 47$ samples $\rightarrow 54.65 \%$

3) Did you ask your orthodontist regarding advantages and disadvantages of anterior microimplant?

- $\quad$ Yes $\rightarrow 48$ samples $\rightarrow 55.81 \%$

- $\quad$ No $\rightarrow 38$ samples $\rightarrow 44.19 \%$

4) Did you inquire about the time for the placement of anterior microimplant?

- $\quad$ Yes $\rightarrow 49$ samples $\rightarrow 56.98 \%$

- $\quad$ No $\rightarrow 37$ samples $\rightarrow 43.02 \%$

5) Were you worried about how long the anterior microimplant will remain in your mouth?

- $\quad$ Yes $\rightarrow 76$ samples $\rightarrow 88.37 \%$

- $\quad$ No $\rightarrow 10$ samples $\rightarrow 11.63 \%$

6) Did you develop fear in your mind when you came to know that the procedure will be done under local anaesthesia?

- $\quad$ Yes $\rightarrow 71$ samples $\rightarrow 82.56 \%$

- $\quad$ No $\rightarrow 15$ samples $\rightarrow 17.44 \%$

- After placement of anterior microimplant

7) Was the procedure pleasant and comfortable for you?

- $\quad$ Yes $\rightarrow 70$ samples $\rightarrow 81.39 \%$

- $\quad$ No $\rightarrow 16$ samples $\rightarrow 18.61 \%$

8) Did you feel pain during or after placement of anterior microimplant?

- $\quad$ Yes $\rightarrow 38$ samples $\rightarrow 44.19 \%$

- $\quad$ No $\rightarrow 48$ samples $\rightarrow 55.81 \%$

9) What was your feeling when an orthodontic attachment was put from the anterior implant to the teeth for force application?

- $\quad$ Pressure at the implant $\rightarrow 65$ samples $\rightarrow 75.58 \%$

- $\quad$ Pain in the teeth $\rightarrow 04$ samples $\rightarrow 4.65 \%$

- $\quad$ Both $\rightarrow 17$ samples $\rightarrow 19.77 \%$

10) Are you satisfied with the treatment by anterior implant so far?

- $\quad$ Yes $\rightarrow 79$ samples $\rightarrow 91.86 \%$

- $\quad$ No $\rightarrow 07$ samples $\rightarrow 8.14 \%$

11) Would you recommend it to other patients?

- $\quad$ Yes $\rightarrow 75$ samples $\rightarrow 87.21 \%$

- $\quad$ No $\rightarrow 11$ samples $\rightarrow 12.79 \%$

12) By what day did you get used to the anterior implant?

- $\quad$ Day $1 \rightarrow 5$ samples $\rightarrow 5.81 \%$
- $\quad$ Day $2 \rightarrow 6$ samples $\rightarrow 6.98 \%$

- $\quad$ Day $3 \rightarrow 8$ samples $\rightarrow 9.30 \%$

- $\quad$ Day $4 \rightarrow 6$ samples $\rightarrow 6.98 \%$

- $\quad$ Day $5 \rightarrow 8$ samples $\rightarrow 9.30 \%$

- $\quad$ Day $6 \rightarrow 3$ samples $\rightarrow 3.49 \%$

- $\quad$ Day $7 \rightarrow 29$ samples $\rightarrow 33.72 \%$

- $\quad$ Day $15 \rightarrow 14$ samples $\rightarrow 16.28 \%$

- $\quad$ Day $30 \rightarrow 5$ samples $\rightarrow 5.81 \%$

- Could not get used to it $\rightarrow 2$ samples $\rightarrow 2.32 \%$

13) What is the time period do you think is acceptable for anterior implant?

- 1 month $\rightarrow 7$ samples $\rightarrow 8.14 \%$

- 2 months $\rightarrow 6$ samples $\rightarrow 6.98 \%$

- 4 months $\rightarrow 8$ samples $\rightarrow 9.30 \%$

- 6 months $\rightarrow 10$ samples $\rightarrow 11.63 \%$

- 12 months $\rightarrow 33$ samples $\rightarrow 38.37 \%$

- 24 months $\rightarrow 6$ samples $\rightarrow 6.98 \%$

- Till the orthodontic treatment is over $\rightarrow 16$ samples $\rightarrow 18.60 \%$

\section{Discussion}

Implants have gained popularity in orthodontics because they facilitate maximum anchorage with minimum patient cooperation. However, some orthodontists avoid using implants because perception and experience of patients towards such anchorage systems is questionable and is not been fully reported (TakanoYamamoto T et al 2002 p.26; Gündüz E et al 2004 p.623).

Microimplants are more frequently used in the anterior region than any other intraoral sites especially the upper anterior region for intrusion of maxillary teeth. The literature has very less reports addressing the perception and experience of the patients to the treatment using microimplants in the anterior region and its acceptance. Hence an attempt was made here to conduct a study to evaluate the patient's perception and experience towards anterior implants for intrusion of anterior teeth.

Here in this study, sample was evaluated by dividing the questionnaire into two parts, i.e. before placement of the anterior microimplant to determine their perception and after placement of anterior microimplant to determine their experience towards anterior microimplant.

Determining the patient's perception towards anterior microimplant, the results of this study indicate that out of 86 subjects, $61(70.93 \%)$ patients created doubt in their mind when they were informed about placement of anterior microimplant in their mouth whereas $25(29.07 \%)$ patients did not create any doubt for the same. This finding coincides with the findings of Larissa Bustamante Capucho Brandão and José Nelson Mucha (Brandão LBC \& Mucha JN 2008 p.118) who found that 
$20 \%$ of the patients did not pose any questions regarding the miniimplants, when these devices were first suggested.

Every patient was asked whether they thought to take second opinion when the treatment with anterior microimplant was recommended. Result shows that $39(45.35 \%)$ patients answered that they thought to take second opinion whereas 47 (54.65\%) patients had enough confidence on their orthodontist and didn't show interest to take a second opinion. Similar result was found in study of Elif Gündüz et al (Gündüz E 2004 p.623) who evaluated that $60 \%$ of their patients said that they have full confidence on their orthodontist and therefore they did not think to take second opinion for the treatment with palatal implant.

Out of 86 subjects, $48(55.81 \%)$ patients asked their orthodontist regarding advantages and disadvantages of anterior microimplant whereas $38(44.19 \%)$ patients did not ask about the same. The similar finding was found by Elif Gündüz et al (Gündüz E et al 2004 p.623) in their questionnaire study on palatal implant which is a very healthy conversation expected from any patient.

Regarding the time period for the procedure of anterior microimplant placement, 49 (56.98\%) patients answered that they inquired to orthodontist regarding required time period for the placement of anterior microimplant whereas $37(43.02 \%)$ patients did not inquire regarding the same. This is also a very usual question that any patient would inquire about.

When patients were asked whether they worried about how long the anterior microimplant will remain in their mouth, $76(88.37 \%)$ patients answered 'Yes' and $10(11.63 \%)$ patients answered 'No'. It is obvious that after getting explained about the anterior microimplant and the procedure of its placement various questions come in patient's mind such as how long this implant will remain in mouth, whether it will remain for few days or it will remain till the orthodontic treatment gets over. Thus here in this study it was not surprising that most of the patients asked question that how long the microimplant will remain in their mouth. However this finding is not in agreement with the findings of Larissa Bustamante Capucho Brandão and José Nelson Mucha (Brandão LBC \& Mucha JN 2008 p.118) who found in their study that only $10 \%$ patients showed concern about how long miniimplants will remain inserted.

It is very important to know about the fear of patient that develops in their mind when they are informed that treatment will be done under local anesthesia. In this study out of 86 patients, $71(82.56 \%)$ patients developed fear in their mind when they came to know that procedure for placement of anterior microimplant will be done under local anesthesia whereas $15(17.44 \%)$ patients did not develop any fear after knowing about such procedure.

Determining the experience of patients after placement of anterior microimplant, results of this study indicate that most of the patients $(81.39 \%)$ felt that procedure of anterior microimplant placement was pleasant and comfortable whereas very few patients $(18.61 \%)$ were not comfortable with this procedure. Nowadays, treatment of deep bite with anterior microimplant is very routine treatment protocol and the clinicians are well trained and experienced. Therefore such procedure can be performed very comfortably.

When patients were asked about experience of pain after placement of anterior microimplant, out of 86 patients, $38(44.19 \%)$ answered they felt pain whereas $48(55.81 \%)$ patients did not felt any pain after placement of microimplant. Perception of pain varies from patient to patient and their pain threshold. Other factors that affect the perception of pain are method of insertion of implant, method of injecting LA, poor oral hygiene with resultant periimplantitis, etc.

Finding of this study shows that when patients were asked about the feeling after loading the microimplant, majority of the patients $(75.58 \%)$ felt pressure at the implant site, whereas four patients $(4.65 \%)$ felt pain in the teeth attached for intrusion. Interestingly, $17(19.77 \%)$ patients felt both pressure at implant as well as pain in the teeth.

Out of 86 patients, $79(91.86 \%)$ patients were satisfied with the treatment by anterior implant so far and most of the patient
(87.21\%) would recommend it to other patients. Similar findings were shown by Elif Gündüz et al (Gündüz E et al 2004 p.623) and Larissa Bustamante Capucho Brandão \& José Nelson Mucha (Brandão LBC \& Mucha JN 2008 p.623) for their studies on palatal implant and microimplant respectively.

By $7^{\text {th }}$ day, majority of the patients $(33.72 \%)$ got used to the anterior micro implant. Some patients $(16.28 \%)$ got used to anterior microimplant by 15 days and there were only two patients who could not get used to the microimplant. As this microimplant is placed in anterior region, initially there may be difficulty such as speech difficulty, irritation to lip and irritation due to food lodgment. Thus most of the patients need time period around a week to get used to it. Elif Gündüz et al (Gündüz E 2004 p.623) found in his study that patients need about 2 weeks to 3 months to get used to the palatal implant in the palate.

Microimplants once inserted can remain in their insertion sites throughout the treatment as it may be needed again during treatment and removed only when the orthodontic treatment is over. Therefore it is also important to know that how longer the patient allows anterior microimplant inserted in mouth. In this study most of the patients $(38.37 \%)$ answered that the time period of 12 months is acceptable for anterior microimplant. Elif Gündüz et al (Gündüz E et al 2004 p.623) found in their study that an average time period of 24 months is accepted for palatal implant. This finding is not in agreement with this study as in the present study only $6.97 \%$ of patients replied that 24 months is acceptable time period for anterior microimplant.

\section{Conclusions}

1) Most of the patients developed a doubt when they were informed about placement of anterior microimplant.

2) More number of patients had enough confidence on their orthodontist and did not think to take a second opinion when an anterior implant was recommended by orthodontist.

3) Majority of the patients were concerned to know regarding advantages and disadvantages of anterior microimplant and inquired about the time for the placement of anterior microimplant.

4) More patients were worried about how long the anterior microimplant will remain inserted in their mouth and had fear of local anaesthesia.

5) The procedure was pleasant and comfortable for large number of patients and they did not feel pain after placement of anterior microimplant.

6) When attachment was put from the anterior implant to the teeth for force application most of the patients felt pressure at the implant. Majority of the patient were satisfied with the treatment and would recommend it to other patients.

7) Highest number of patients did get used to the anterior implant by day 7 followed by day 15 . An average acceptable time period for the anterior microimplant was 12 months by most patients.

The overall perception and experience by the patients to the placement of anterior microimplant can be rated as expected and good.

\section{References}

[1] Takano-Yamamoto T, Miyawaki S, Koyama I. Can implant orthodontics change the conventional orthodontic treatment? Dental Diamond 2002; 27: 26-47.

[2] Gündüz E, Schneider-Del Savio TT, Kucher G, Schneider B, Bantleon HP. Acceptance rate of palatal implants: A questionnaire study. Am J Orthod Dentofacial Orthop 2004; 126: 623- 6? https://doi.org/10.1016/j.ajodo.2004.06.031

[3] Miyawaki S, Koyama I, Inoue M, Mishima K, Sugahara T, TakanoYamamoto T. Factors associated with the stability of titanium screws placed in the posterior region for orthodontic anchorage. 
Am J Orthod Dentofacial Orthop 2003; 124: 373-8. https://doi.org/10.1016/S0889-5406(03)00565-1.

[4] Liou EJ, Pai BC, Lin JC. Do miniscrew remain stationary under orthodontic forces? Am. J. Orthod. Dentofacial Orthop. 2004; 126:42-7. https://doi.org/10.1016/j.ajodo.2003.06.018.

[5] Freundenthaler JW, Haas R, Bantleon HP. Bicortical titanium screws for critical orthodontic anchorage in the mandible: a preliminary report on clinical applications. Clin Oral Implants Res. 2001; 12: 358-63.

https://doi.org/10.1034/j.1600-0501.2001.012004358.x.

[6] Kuroda S, Sugawara Y, Deguchi T, Kyung HM, TakanoYamamoto T. Clinical use of miniscrew implants as orthodontic anchorage: Success rates and postoperative discomfort. Am J Orthod Dentofacial Orthop. 2007; 131:9-15 https://doi.org/10.1016/j.ajodo.2005.02.032.

[7] Hyo-Sang P, Eun-Seok H, Tae-Geon K. Proper mesiodistal angles for microimplant placement assessed with 3-dimensional computed tomography images. Am J Orthod Dentofacial Orthop 2010; 137: 200-6. https://doi.org/10.1016/j.ajodo.2008.04.028.

[8] Brandão LBC, Mucha JN. Rate of mini-implant acceptance by patients undergoing orthodontic treatment - A preliminary study with questionnaires. Dental press J Orthod 2008; 13: 118-27. 